\title{
The Role of Montmorillonite Loading on the Physicochemical Properties of Regenerated Cellulose Nanocomposite Films Obtained from Microcrystalline Cellulose
}

\author{
P. R. D. Weerasooriya, ${ }^{1}$ S. N. Ain Jamal, ${ }^{1}$ M. K. Mohamad Haafiz, ${ }^{1 *}$ H. P. S. Abdul \\ Khalil, ${ }^{1}$ Noor Haida Mohd Kaus, ${ }^{2}$ A. N. Amalini ${ }^{1}$ and Salim Hiziroglu ${ }^{3}$ \\ ${ }^{1}$ School of Industrial Technology, Universiti Sains Malaysia, \\ 11800 USM Pulau Pinang, Malaysia \\ ${ }^{2}$ School of Chemical Sciences, Universiti Sains Malaysia, \\ 11800 USM Pulau Pinang, Malaysia \\ ${ }^{3}$ Department of Natural Resource Ecology and Management, Oklahoma State University, \\ Stillwater, Oklahoma 74078-6013, United States \\ *Corresponding author: mhaafiz@usm.my
}

Published online: 25 April 2020

To cite this article: Weerasooriya, P. R. D. et al. (2020). The role of montmorillonite loading on the physicochemical properties of regenerated cellulose nanocomposite films obtained from microcrystalline cellulose. J. Phys. Sci., 31(1), 85-103. https://doi.org/10.21315/ jps2020.31.1.6

To link to this article: https://doi.org/10.21315/jps2020.31.1.6

\begin{abstract}
The objective of this study was to find the optimum amount of montmorillonite (MMT) to be incorporated with microcrystalline cellulose (MCC) to enhance physicochemical properties of oil palm empty fruit bunch (OPEFB)-based regenerated cellulose $(R C)$. In this research, $R C$ was synthesised by mixing $6.5 \mathrm{wt} \%$ of OPEFB-MCC with 1-butyl,3-methylimidazolium chloride [BMIM]Cl ionic liquid at $75^{\circ} \mathrm{C}$ by continuous stirring. $R C$ nanocomposites were prepared by adding $1-5 \mathrm{wt} \%$ of montmorillonite (MMT) into RC preparation base. Finished solutions of both types were subjected to solution casting process to obtain thin films. Fourier transformation infrared (FTIR) spectroscopy, tensile test, scanning electron microscopy (SEM), thermogravimetric analysis (TGA), water absorption and contact angle measurements were used as the characterisation tools. FTIR spectroscopy denotes the non-derivative behaviour of [BMIM]Cl ionic liquid. According to SEM images, moderate MMT loading is preferred since high MMT loading shows coarse morphology beyond 3 wt\% of MMT. Tensile strength of RC $11 \mathrm{MPa}$ was increased up to $30 \mathrm{MPa}$ as maximum in 4 wt\% of MMT loading. Compared with pure RC, TGA curves were shifted to right side with the increased MMT loading and that implies good thermal stability. The highest thermal stability can be seen when the MMT content is 4 wt\% since its TGA curve was
\end{abstract}


the rightmost than others. Therefore, MMT can be identified as a good inhibitor for RC to avoid thermal degradation at elevated temperatures. Water absorption was reduced as $91 \%-37 \%$ in $2 \mathrm{~h}$ and $96 \%-41 \%$ in $24 \mathrm{~h}$ when MMT was increased from $0-5 w t \%$. Similarly, their contact angle was increased from $30.5^{\circ}-88.5^{\circ}$ for the MMT loading of 0-5 wt\%. According to all these results, 3-4 wt\% of MMT loading can be proposed as the optimum amount to be added into an RC matrix to utilise these films in packaging, photocatalytic and electrically conductive applications.

Keywords: Montmorillonite, oil palm empty fruit bunch, regenerated cellulose, nanocomposites, optimum

\section{INTRODUCTON}

Cellulose is considered the most abundant natural polymer polysaccharide on the earth. ${ }^{1,2}$ It has an estimated annual production of $90 \times 10^{9}$ metric tons and represents the most obvious renewable resource for manufacturing of biocomposites. ${ }^{3}$ Cellulose is commonly used in textiles, paper, artificial fibres, paint, food and medical applications. ${ }^{4,5}$ This valuable polymer can be isolated from various raw materials such as post-consumer newspaper, rice husk, agriculture crops and oil palm empty fruit bunch (OPEFB). ${ }^{6-9}$ OPEFB was chosen in order to extract the cellulose from palm oil biomass because of the higher percentage of lignocellulosic composition available in OPEFB. Also, OPEFB is abundantly available in Malaysia (Figure 1) as a biomass waste. ${ }^{10-12}$ Properties of OPEFB can be enhanced by transforming it into micro or nano-scaled materials. ${ }^{6}$ According to Haafiz et al., microcrystalline cellulose (MCC) has been isolated from OPEFB using Battista method by dissolving amorphous regions of cellulose network with the aid of acid hydrolysis. ${ }^{13-15}$

Cellulose is made of $\beta$-D-glucopyranose as the monomer. Cellulose network is formed by intramolecular and intermolecular hydrogen bonds in between layers. ${ }^{16}$ Hence, cellulose has a partially crystalline structure and it brings the high resistance of cellulose to dissolve in many liquids. ${ }^{17}$ Scientists have attempted several solvents to perform efficient dissolution of cellulose. Viscose, carbocell and xanthation are some old derivatising methods whereas lyocell process, cupromonium process, molten salts, aqueous and non-aqueous dissolution are nonderivatising regeneration methods. ${ }^{18}$ In late 90 s, ionic liquids (IL) were identified as a favoured technology for cellulose dissolution with numerous advantages such as good dissolving power, ability to recover solvent, and minimum environmental impacts as a result of being less volatile. ${ }^{19}$ The dissolved solute (cellulose) can be precipitated using an antisolvent which is capable to reduce the solubility of solute in used solvent (i.e., IL) further. ${ }^{20}$ Therefore, cellulose separation 
is facilitated by this process which is known as regeneration. ${ }^{21}$ Compressed $\mathrm{CO}_{2}$, ethanol and water are popular antisolvents. ${ }^{20} \mathrm{RC}$ can be prepared through three-step process: dissolution, shaping and regeneration. ${ }^{22}$ The shape of the regenerated material depends on the regeneration method and conditions. Thin films having a thickness ranging from $0.1 \mathrm{~mm}$ to $0.2 \mathrm{~mm}$ can be obtained by solution casting. Currently, $\mathrm{RC}$ is utilised in food packaging, membrane filtration, medical goods and electronic devices. ${ }^{22}$ In this research, MCC was dissolved inside IL [BMIM] $\mathrm{Cl}$ at $75^{\circ} \mathrm{C}$ followed by shaping and coagulation with distilled water as the antisolvent to obtain $\mathrm{RC}$ thin films as the throughput.

Developing nanocomposites using nanomaterials is an ideal technique to enhance the performance of a basic material. Montmorillonite (MMT) is one of the most popular layered silicate materials widely used in nanocomposites because of its low cost, chemical and thermal stability, high aspect ratio (100-1500) and high surface to volume ratio $\left(700-800 \mathrm{~m}^{2} \mathrm{~g}^{-1}\right) .^{23,24}$ It consists of sodium cations between interlayer spaces and therefore natural MMT is hydrophilic and interactive with hydrophilic polymers. ${ }^{25}$ During the past decade, several researchers have attempted to study the utilisation of nanomaterials (halloysites; HNT, sepiolite and MMT) with commercial MCC to manufacture RC. ${ }^{26-28}$ But incorporation of MMT with OPEFB based MCC has not been addressed yet.

Thus, this research aimed to add MMT different loadings (1-5 wt \%) into an RC synthesising IL solution containing OPEFB based MCC (6.5 wt\%). Physicochemical properties of prepared RC/MMT nanocomposite films were evaluated as explained in Section 2. It is expected to use these RC/MMT films in packaging, photocatalytic and electrically conductive thin film applications. Therefore, the objective of this research was to determine the most appropriate nanomaterial composition to be combined with OPEFB based RC matrix to enhance the performance of RC.

Table 1: Chemical composition of oil palm empty fruit bunch. ${ }^{29}$

\begin{tabular}{lc}
\hline Component & Percentage (\%) \\
\hline Cellulose & 37.26 \\
Lignin & 31.68 \\
Hemicellulose & 14.62 \\
Extractive & 1.34 \\
Ash & 6.69 \\
\hline
\end{tabular}


Table 2: Ingredients of MMT nano material. ${ }^{23}$

\begin{tabular}{lc}
\hline Compound & Amount (\%) \\
\hline $\mathrm{Al}_{2} \mathrm{O}_{3}$ & 18.68 \\
$\mathrm{SiO}_{2}$ & 61.08 \\
$\mathrm{CaO}$ & 2.49 \\
$\mathrm{BaO}$ & 0.17 \\
$\mathrm{MgO}$ & 7.09 \\
$\mathrm{Fe}_{2} \mathrm{O}_{3}$ & 6.00 \\
$\mathrm{Na}_{2} \mathrm{O}$ & 3.63 \\
$\mathrm{~K}_{2} \mathrm{O}$ & 0.42 \\
$\mathrm{NiO}_{2}$ & 0.44 \\
\hline
\end{tabular}

\section{EXPERIMENTAL}

\subsection{Materials}

In this study, IL $[\mathrm{BMIM}] \mathrm{Cl}$ with purity of $\geq 98 \%$ was purchased from Sigma Aldrich. OPEFB was supplied by United Oil Palm, Nibong Tebal, Penang, Malaysia and its composition was displayed in Table 1. MMT was purchased from Nanocor, Arlington Heights, United States and its constituents were displayed in Table 2. Further, $25 \% \mathrm{NaOH}, 32 \% \mathrm{HCl}$ and $\mathrm{NH}_{4} \mathrm{OH}$ were supplied by Merck, Malaysia. As the cellulose stabiliser, tannic acid (TA) extra pure was purchased from $\mathrm{HmbG}$ Chemicals. It is a dark yellowish powder with a melting point of $218^{\circ} \mathrm{C}$. MCC was isolated from OPEFB according to the method described by Haafiz et al. ${ }^{13}$ Initially, OPEFB fibrous strands were pre-hydrolysed at $170^{\circ} \mathrm{C}$ for $60 \mathrm{~min}$. Then, soda pulping was done inside $25 \%$ of $\mathrm{NaOH}$. The mixture obtained after soda pulping is known as total chlorine free (TCF) pulp. It was put for oxygen, ozone and hydrogen peroxide treatments (bleaching). ${ }^{13}$ The bleached pulp was off white. Afterward, the pulp was hydrolysed with $2.5 \mathrm{~N} \mathrm{HCl} \mathrm{(1:20} \mathrm{pulp} \mathrm{to}$ liquor ratio) at $105^{\circ} \mathrm{C} \pm 2^{\circ} \mathrm{C}$ for 30 min with constant agitation using a magnetic stirrer. Then, the mixture was filtered at room temperature and the precipitate was washed by distilled water, $5 \%$ diluted $\mathrm{NH}_{4} \mathrm{OH}$ and again with distilled water until it was free from acid. The wet solid mass was dried under vacuum at $105^{\circ} \mathrm{C} \pm 2{ }^{\circ} \mathrm{C}$ until a constant weight was attained. At the end of this step, dry solid mass could be viewed in snowy-white colour. This was subjected to grinding process using rotatory ball mill to obtain MCC as a fine dust. Before use, the ground product had been kept in a storage bottle. 


\subsection{Preparation of RC/MMT Nanocomposite Films}

Initially, $18.7 \mathrm{~g}$ of [BMIM]Cl was weighed into a $100 \mathrm{ml}$ beaker and it was kept on a temperature controlled magnetic stirrer $\left(\right.$ at $75^{\circ} \mathrm{C}$ ) to obtain liquid [BMIM] $\mathrm{Cl}$. Once it appeared as liquefied IL, $10 \mathrm{ml}$ of it was taken out to allow for MMT dispersion. In each MMT loading ( $0-5 \mathrm{wt} \%)$, the weighed amount of MMT was dispersed in [BMIM]Cl using a sonicator (Branson 1800) operated for $30 \mathrm{~min}$ and subsequently by magnetic stirring $(500 \mathrm{rpm})$ for $4 \mathrm{~h}$ at $75^{\circ} \mathrm{C}$. The remaining IL was mixed at $75^{\circ} \mathrm{C}$ with 2 phc TA by magnetic stirring ( $\left.400 \mathrm{rpm}\right)$ until a clear liquid was observed. Then, $1.3 \mathrm{~g}$ of MCC was applied into the beaker and next MMT dispersion was added. Mixing of MCC and MMT was conducted with continuous stirring at $75^{\circ} \mathrm{C}$ until a clear solution was observed. Then, the solution mixture was cast on a glass plate with the aid of a blade and quickly immersed inside a distilled water bath for coagulation up to $24 \mathrm{~h}$. Once coagulation was completed, films were transferred into a polyethylene sheet. The films were allowed to dry at room temperature and conditioned at $23^{\circ} \mathrm{C} \pm 2^{\circ} \mathrm{C}$ and $50 \%$ relative humidity before characterisation. All films with average thickness of $0.3 \mathrm{~mm}$ were prepared in triplicate and those were coded as MMT-0, MMT-1, MMT-2, MMT-3, MMT-4 and MMT-5 with respect to MMT loading.

\section{$2.3 \quad$ FTIR Spectroscopy}

Attenuated total reflectance Fourier transform infrared spectrometer (ATR-FTIR) IR Prestige-21, Shimadzu, Japan was used to characterise the chemical structure of prepared thin films. The films were clamped between the horizontal crystals and robust pressure clamp. The infrared spectrums were obtained within the wave number range of 600-4000 $\mathrm{cm}^{-1}$. The significant transmittance peak at a particular wave number was measured with the aid of Find Peak tool provided by Nicolet OMNIC 5.01 software.

\section{$2.4 \quad$ Tensile Test}

ISO1924-2 method was selected to evaluate the mechanical behaviour of RC films. The RC films were uniformly cut into strips $(140 \mathrm{~mm} \times 15 \mathrm{~mm} \times 0.03 \mathrm{~mm})$ before clamping them on tensile testing machine (F81.50200, Frank-PTI, Birkenau, Germany) with respect to the standard ISO1924-2.

Initially, the thickness of each sample was measured with the aid of micrometre screw gauge on three distinct positions along the length and the mean value was multiplied by a $15 \mathrm{~mm}$ width of the sample to calculate the effective cross-sectional area. The initial grip separation and load cell value were $100 \mathrm{~mm}$ and $500 \mathrm{~N}$, 
respectively. For every film, average values of five different measurements were taken to calculate the mean tensile strength (TS) $(\sigma=\mathrm{F} / \mathrm{A})$ and elongation at break (EAB) (Strain $€=e / L)$. Young's modulus (E) was calculated by using Equation 1 based on Hook's law:

$$
(\mathrm{F} / \mathrm{A})=\mathrm{E}(\mathrm{e} / \mathrm{L})
$$

where $\mathrm{F}$ is the load $(\mathrm{N}), \mathrm{A}$ is the effective cross-sectional area $\left(\mathrm{mm}^{2}\right)$, e is tensile displacement $(\mathrm{mm})$ and $\mathrm{L}$ is initial length $(140 \mathrm{~mm})$.

\subsection{SEM}

Scanning electron microscopy (SEM) was used to examine the molecular arrangement of the RC nanocomposite films. Leo Supra 50 VP, Carl Ziess, 5MT Field Emission SEM (Radeberg, Germany) was used for this experiment. Since the films are non-conductive, gold sputtering was made prior to analysis of crosssectional view of films that were subjected to tensile test.

\subsection{Thermogravimetric Analysis}

Thermal analysis was performed using Perkin Elmer-YGA7 (Radebergy, Germany) instrument. Approximately $10 \mathrm{mg}$ of each film was cut into fine pieces and the particle size was reduced using motor and pestle. Then, those were placed on the sample holder and subjected for heating from room temperature to $600^{\circ} \mathrm{C}$ with a scan rate of $10^{\circ} \mathrm{C} \mathrm{min}^{-1}$ under nitrogen atmosphere.

\subsection{Water Absorption Measurement}

ASTM D570 standard was followed to perform water absorption test in this research. The films were arranged into a square shape of $20 \times 20 \mathrm{~mm}^{2}$ and those were dried at $40^{\circ} \mathrm{C}$ for $24 \mathrm{~h}$ until a constant weight was attained prior to analysis. Then the films were immersed in distilled water at $25^{\circ} \mathrm{C}$ for $2 \mathrm{~h}$ and $24 \mathrm{~h}$. Wet weight of the films were recorded by measuring the weight after completion of immersion time. The percentage of water absorption of each sample for every formulation was recorded using Equation 2:

$$
\text { Water absorption }=\left(\mathrm{W}_{\mathrm{w}}-\mathrm{W}_{\mathrm{i}}\right) / \mathrm{W}_{\mathrm{i}} \times 100 \%
$$

where $\mathrm{W}_{\mathrm{w}}$ is the wet weight after immersion and $\mathrm{W}_{\mathrm{i}}$ is the constant weight attained by long drying before immersion. 


\subsection{Contact Angle Measurement}

The contact angle of RC/MMT films was measured by Attension KSV CAM 101 supplied from KSV Instruments Ltd., Finland as per sessile drop method. Two films of $20 \times 20 \mathrm{~mm}^{2}$ size were placed on a rectangular slide for each formulation. The test liquid deionised water was applied on the surface of the films by a micro syringe. Subsequently, the images were recorded at a speed of 40 frames s$^{-1}$. The contact angle value of a particular film was taken as an average of five different measurements in different parts of two samples prepared per each formulation.

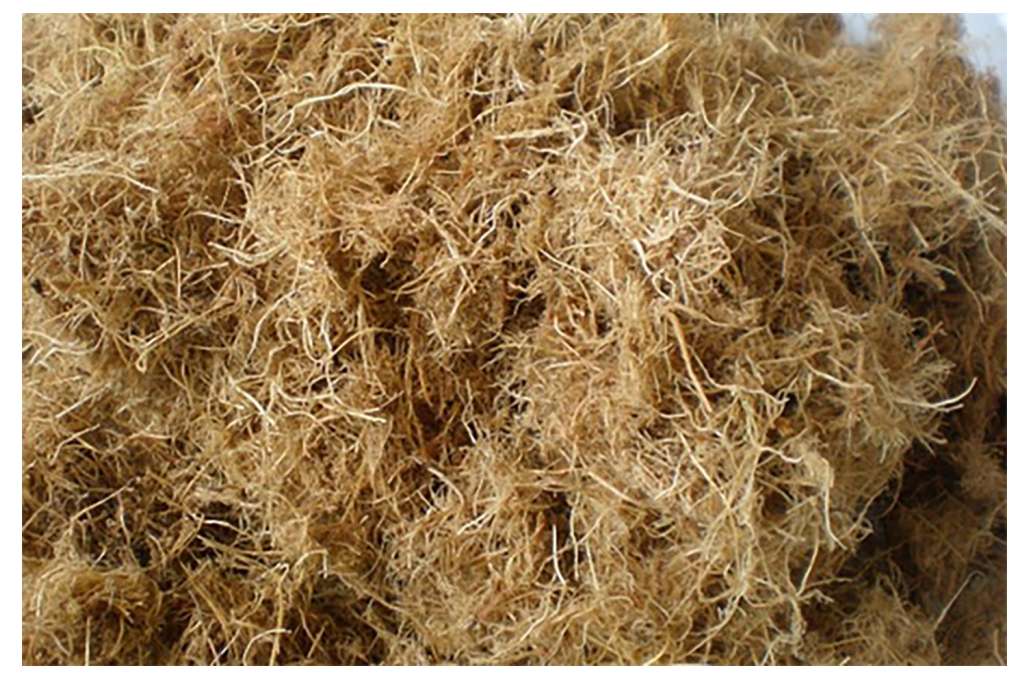

Figure 1: The cellulose source OPEFB.

\section{RESULTS AND DISCUSSION}

\subsection{Chemical Behaviour of RC/MMT Nanocomposite Films}

Evaluation of chemical stability of the system is a mandatory requirement in this kind of study. Figure 2 depicts the FTIR spectrums obtained for MCC, pure RC, $3 \mathrm{wt} \%$ and $5 \mathrm{wt} \%$ MMT added RC films and [BMIM]Cl. It is interesting to note that there are no new peaks displayed in $\mathrm{RC}$ spectrum as well as in RC/MMT spectrums compared with MCC. Therefore, it proves that $[\mathrm{BMIM}] \mathrm{Cl}$ is a nonderivatising solvent for OPEFB-based MCC in which no chemical reactions were accomplished during the regeneration process. ${ }^{30}$ Again, it can be proved that MMT addition does not alter the chemical structure of RC since the curves are almost similar. Table 3 describes the motions corresponding to the significant peaks. The FTIR spectrums are aligned with those wave numbers identical to 
cellulose ${ }^{31}$ However, when it comes to the addition of MMT nanoparticles, the spectrums have slightly shifted to low wave numbers compared with pure RC. The strong interaction of MMT with cellulose is the reason behind that observation according to Majdzadeh-Ardakani et al. ${ }^{25}$ According to Figure 2, RC spectrum does not comprise peaks corresponding to [BMIM]Cl only. Therefore, this proves that [BMIM] Cl was removed out in $24 \mathrm{~h}$ coagulation. Also, [BMIM] $\mathrm{Cl}$ is a gel at ambient temperature (melting point $\approx 70^{\circ} \mathrm{C}$ ) and it causes surface wetting. Since the obtained films had adequate dryness at ambient conditions, it can be concluded that $[\mathrm{BMIM}] \mathrm{Cl}$ is not retained on RC/MMT films after conditioning.

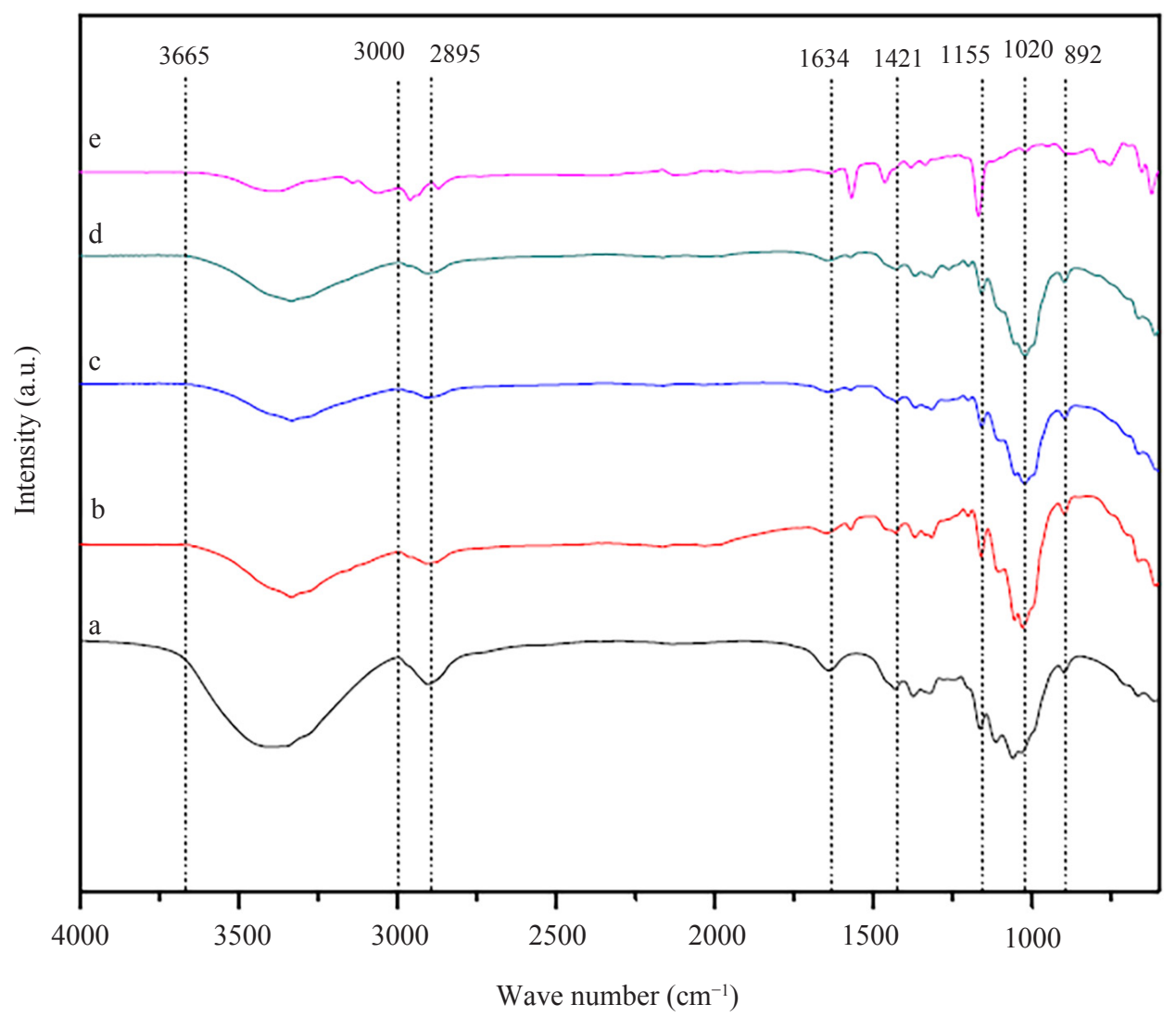

Figure 2: FTIR spectrums obtained for (a) MCC, (b) RC(MMT-0), (c) MMT-3, (d) MMT-5 films, and (e) [BMIM]Cl. 
Table 3: Characteristic FTIR peaks and corresponding motions of organic bonds. . $^{13,31-33}$

\begin{tabular}{ll}
\hline Wave number $\left(\mathrm{cm}^{-1}\right)$ & Bond and motion \\
\hline $3665-3000$ & O-H stretching \\
2895 & C- $\mathrm{H}_{2}$ alkyl stretching \\
1634 & Water absorption \\
1421 & C- $\mathrm{H}_{2}$ alkyl bending stretching \\
1155 & C-O-C pyranose ring skeletal vibrations \\
1020 & C-O stretching \\
892 & C-H rock vibration of cellulose (anomeric vibration; specific for \\
& B-glucosidic water) \\
\hline
\end{tabular}

\subsection{Mechanical Behaviour and Morphology}

The variation of TS and EAB with respect to MMT content is shown in Figure 3. TS of pure $\mathrm{RC}$ which is $11 \mathrm{MPa}$ has increased to $30 \mathrm{MPa}$ as maximum when the MMT content is $4 \mathrm{wt} \%$. Some previous studies have reported that the addition of nanocomposites has significant improvement on the mechanical behaviour of pure RC films. This can be assigned that the nanocomposites and the polymer matrix have strong interaction that restricts the movement of polymer chains..$^{26,27}$

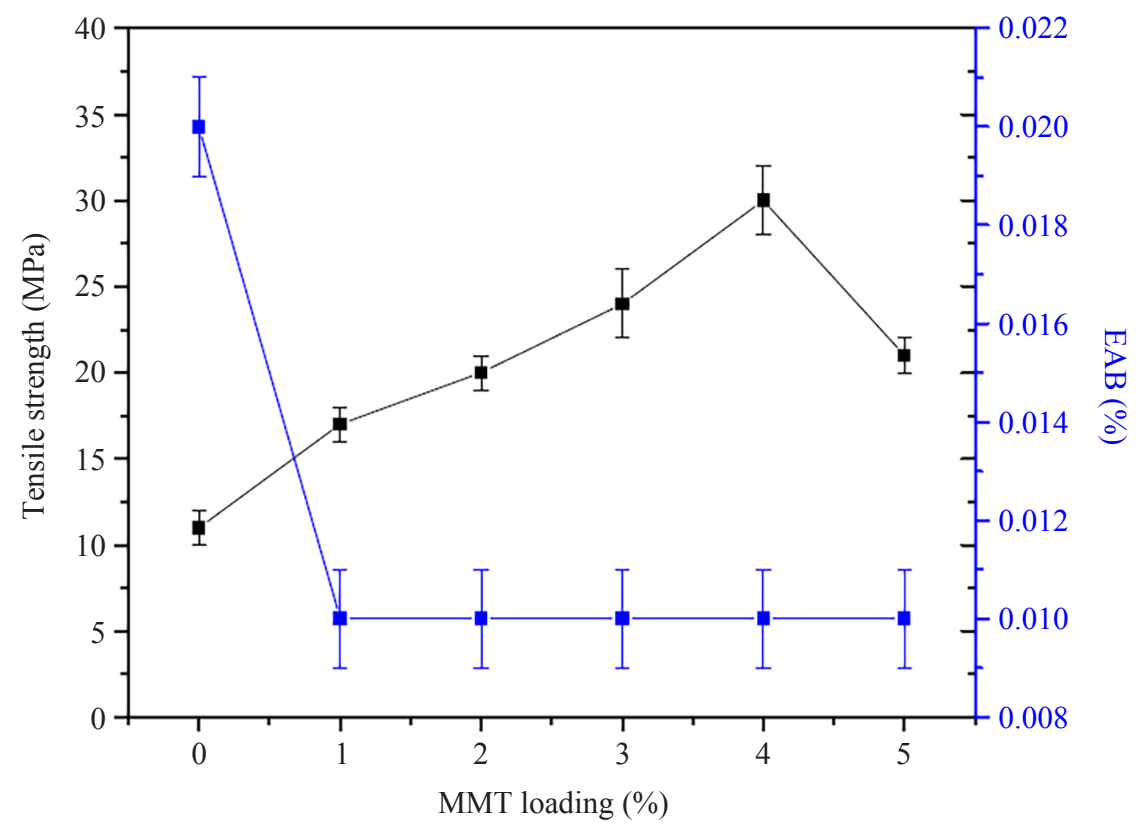

Figure 3: Tensile strength and elongation at break variation of RC films with added MMT content. 
However, the TS of the films shows a reduction from $30 \mathrm{MPa}$ to $21 \mathrm{MPa}$ when the MMT loading is increased from $4 \mathrm{wt} \%$ to $5 \mathrm{wt} \%$. According to Mahmoudian et al., the TS is decreased when the MMT loading is further increased because of the aggregation of MMT particles. Aggregation of MMT particles hinders its basic function and the matrix becomes as a low loading MMT. Therefore, the TS tends to reduce. ${ }^{28}$

EAB has showed a decreasing trend with the presence of MMT. When the MMT content was increased from $0 \mathrm{wt} \%$ to $1 \mathrm{wt} \%$, EAB has decreased from $0.02 \%$ to $0.01 \%$ and remained constant in every MMT loading. According to Hanid et al., the presence of MMT restrains the slippage movement of $\mathrm{RC}$ chains during deformation and it affects the reduction of EAB with MMT incorporation. ${ }^{26}$ But further MMT loading in this range has not affected EAB.

Figure 4 shows SEM images of MMT-O, MMT-3 and MMT-5 films. According to the micrographs in Figures 4(a and b), RC films have homogeneous and denser surface with $6.5 \mathrm{wt} \%$ of MCC in its pure form. However, Figures $4(\mathrm{c}$ and d) with the addition of $3 \mathrm{wt} \%$ MMT depict a smooth interaction of MMT with MCC. But when MMT loading is increased up to $5 \mathrm{wt} \%$ as illustrated in Figures 4(e and f), the cross-section images show a coarse structure as a result of aggregation of MMT particles at high loading. ${ }^{28}$ Also, dark spots in SEM image of $5 \mathrm{wt} \%$ MMT indicates the voids of structure that originated as a result of releasing MMT agglomerates during tensile test due to the stress concentration at agglomerates. ${ }^{26}$ This observation proves the explanation made by Mahmoudian et al. on the reduction of TS at high MMT loadings..$^{28}$

\subsection{Thermal Behaviour of RC/MMT Nanocomposite Films}

Thermogravimetric analysis (TGA) was conducted to determine the effect of MMT on thermal stability of RC. TGA curves of the prepared nanocomposites films with different percentages of weight are shown in Figure 5(I). Further the derivative thermographic (DTG) curves were plotted in Figure 5(II). According to the plot, curves were shifted right side when the MMT loading was increased beyond $2 \mathrm{wt} \%$. Figure 6 depicts $\mathrm{T}_{20}$, the temperature at which $20 \%$ of weight loss had occurred, $\mathrm{T}_{\max }$, the temperature at which maximum weight loss can be observed and residue content. According to these data, in high MMT loading, thermal degradation temperature is increased compared with pure RC. Further residue content after the test is higher when MMT is introduced into RC which implies that degradation temperature can be increased by incorporating MMT nanoparticles on RC matrix. 

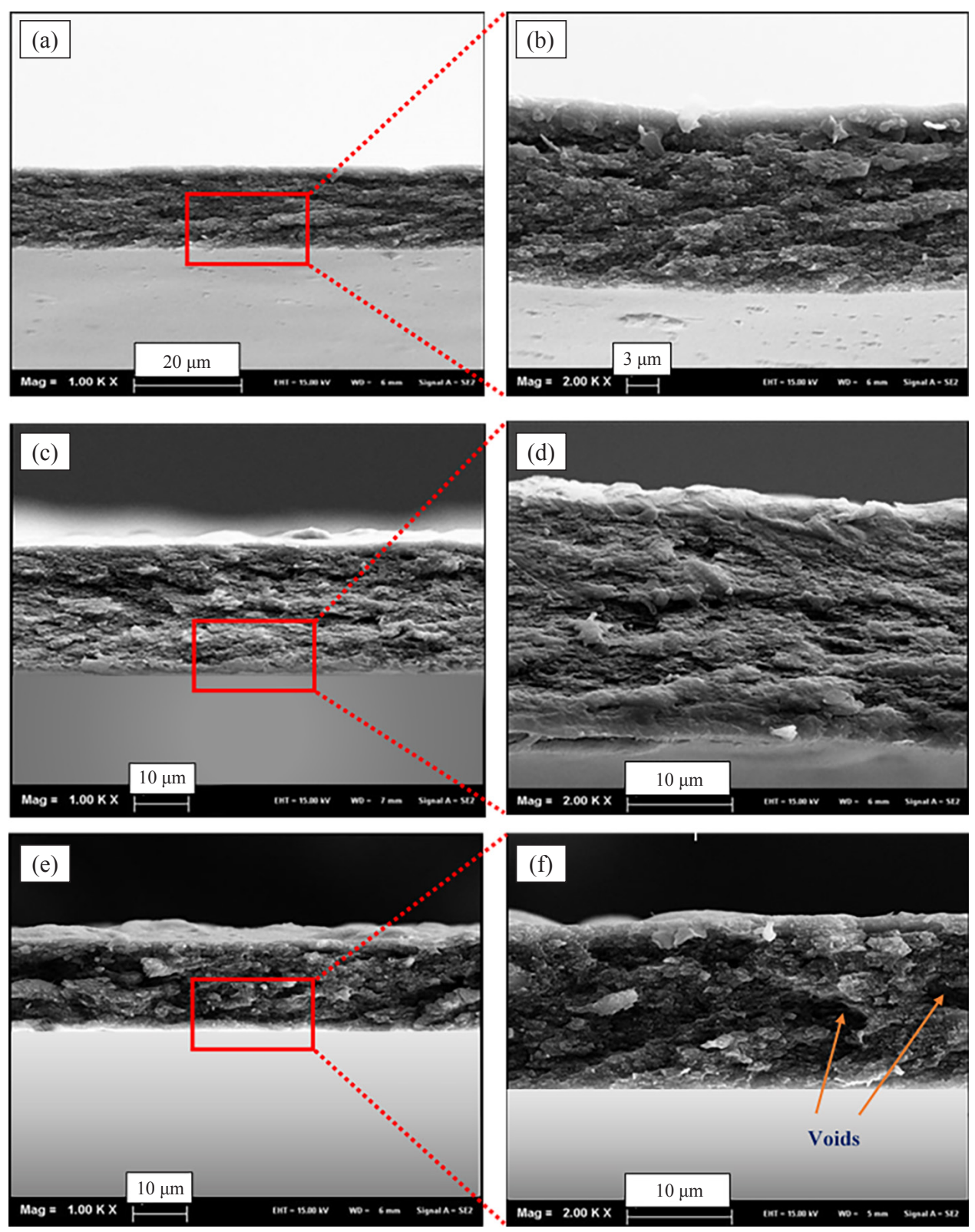

Figure 4: Cross-sectional SEM images of films for (a and b) MMT-O, (c and d) MMT-3, and (e) MMT-5. Images captured using different magnifications, i.e., 1000X for $\mathrm{a}, \mathrm{c}$ and $\mathrm{e}$, and 2000X for $\mathrm{b}, \mathrm{d}$ and $\mathrm{f}$. 


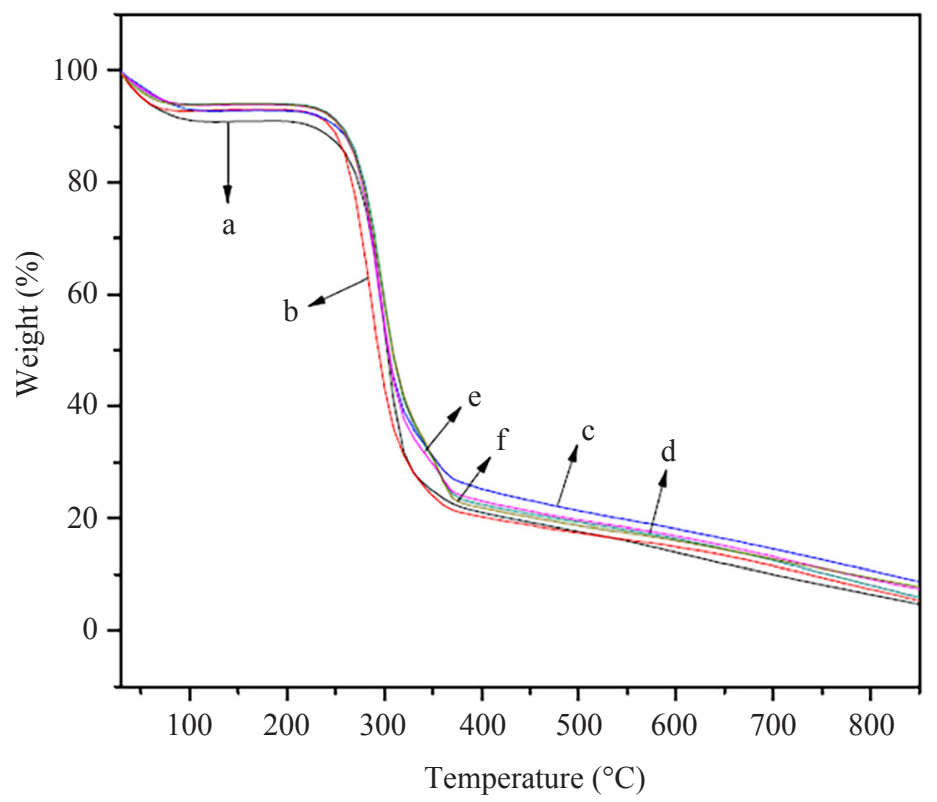

(I)

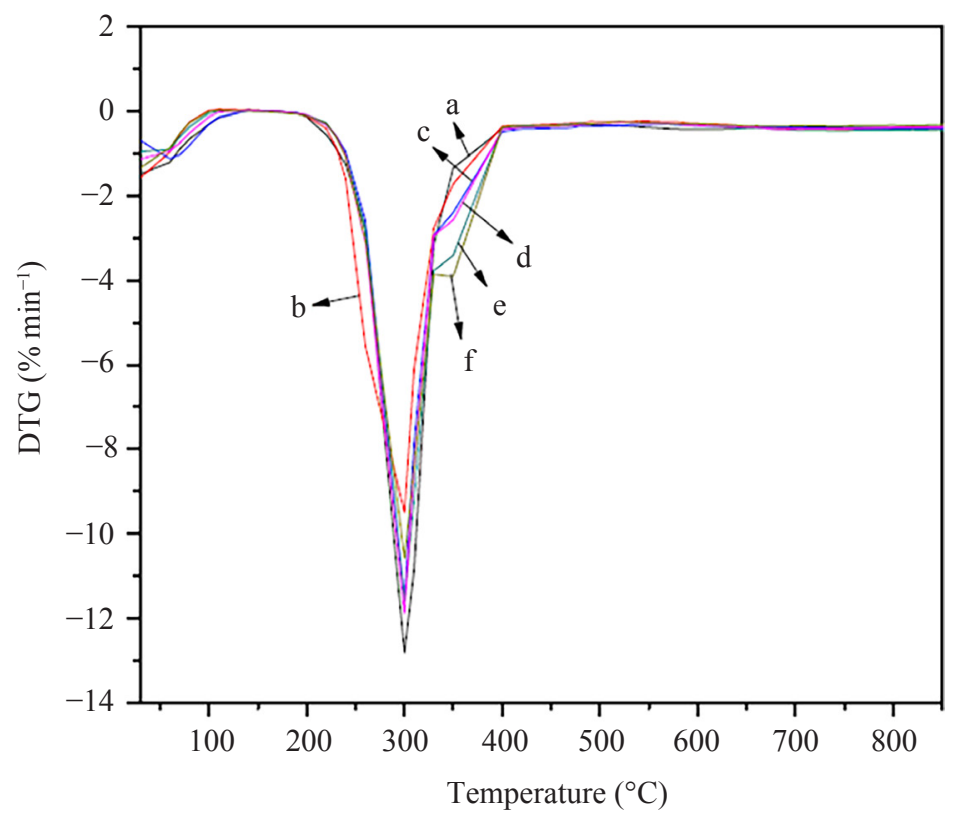

(II)

Figure 5: Illustrations of (I) TGA curves, and (II) DTG curves for (a) MMT-0, (b) MMT-1, (c) MMT-2, (d) MMT-3, (e) MMT-4, and (f) MMT-5 films. 


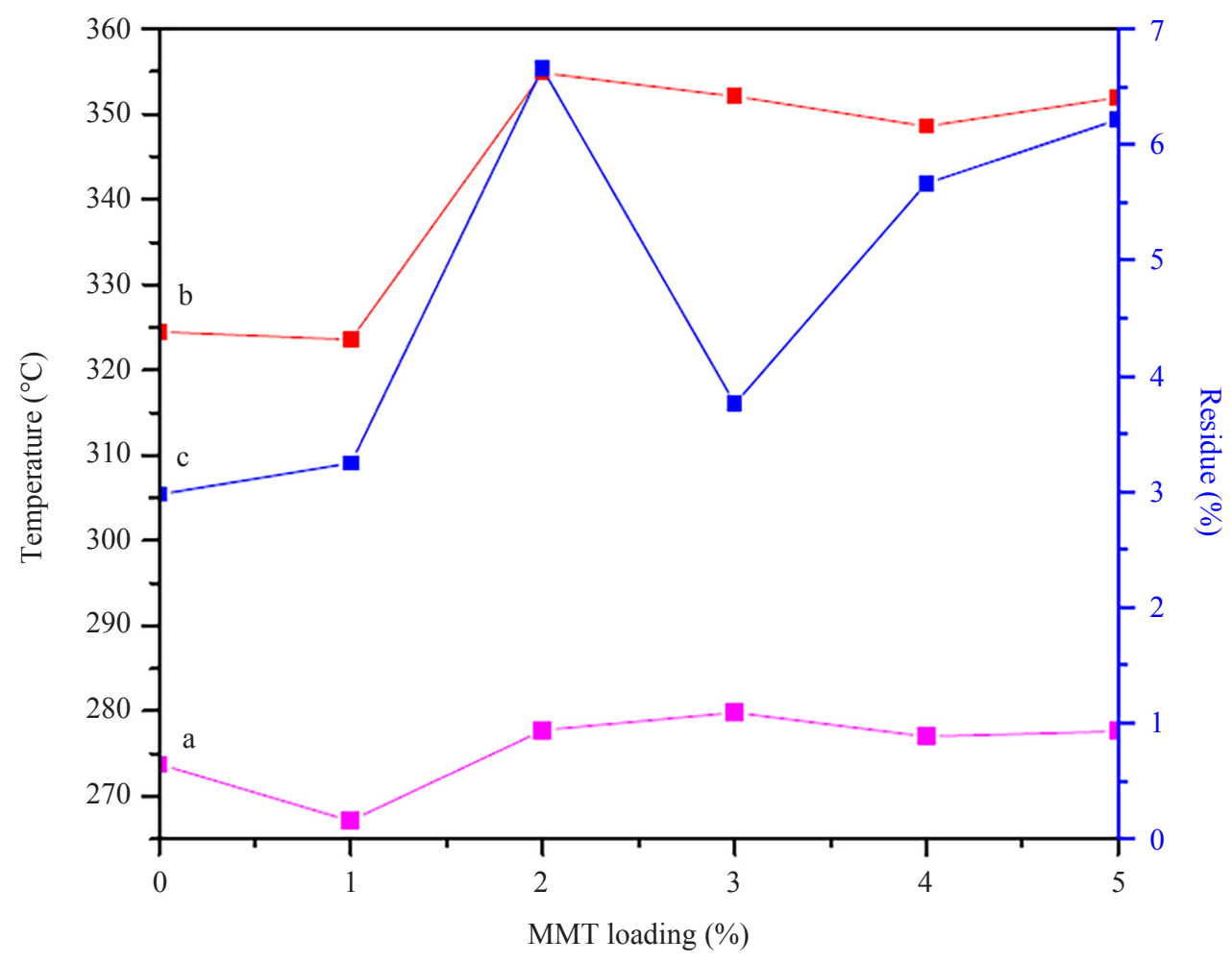

Figure 6: Variation of (a) $\mathrm{T}_{20}$, (b) $\mathrm{T}_{\max }$, and (c) residue content with MMT loading when the films were subjected to temperature sweep.

Hanid et al. have explained that the reason for the increase of thermal stability is the good interaction of MMT with cellulose. Therefore, TGA experiment states that MMT can interact well with $\mathrm{RC}$ which is advantageous in enhancing the thermal properties of pure $\mathrm{RC}^{26}$

According to Figure 6, residue content at $3 \mathrm{wt} \%$ of MMT is less than that in $2 \mathrm{wt} \%$ of MMT. According to Mahmoudian et al., residue content is responsible for the amount of char formation in thermal degradation. The reduction of residue content may be due to the decomposition of octadecylamine which is added into MMT 1.30TC galleries during its modification. Again residue content is increased with MMT loading beyond $3 \mathrm{wt} \%$ of MMT since MMT platelets (impermeable) hinder thermal diffusion through the film. ${ }^{28}$ 


\subsection{Water Resistance of RC/MMT Nanocomposite Films}

Determination of water absorption is a mandatory requirement for films used for packaging, photocatalytic and electrically conductive applications. Figure 7 shows the water absorption capability of prepared films after $2 \mathrm{~h}$ and $24 \mathrm{~h}$ of immersion times. It can be observed that pure RC films have the highest percentage of water absorption compared with RC/MMT nanocomposites films. According to the water absorption values after $24 \mathrm{~h}$, the water absorption of nanocomposite films has decreased from $95.88 \%$ to $40.53 \%$ when the MMT loading is increased up to $5 \mathrm{wt} \%$ starting from pure RC. According to Mahmoudian et al., the presence of MMT in cellulose improves the water resistance of RC/MMT nanocomposite films because of the interference of impermeable MMT particles in reducing the rate of water transport in the polymer matrix..$^{28}$ This result is quite similar to that of Hanid et al. for halloysites (HNT) nanocomposites. ${ }^{26}$

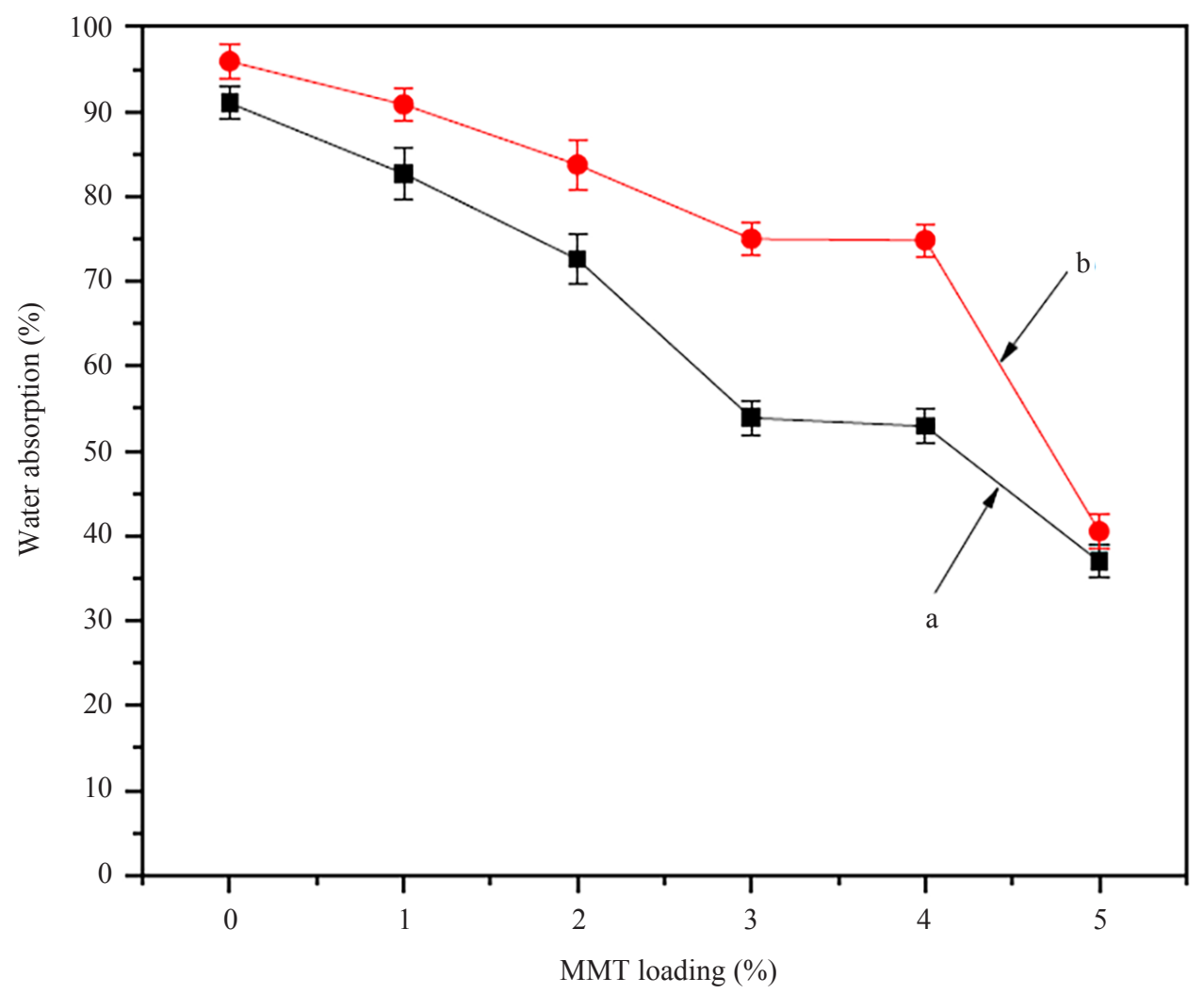

Figure 7: Percentage of water absorption of RC films with added MMT content after immersing in water for $2 \mathrm{~h}$ (line a) and $24 \mathrm{~h}$ (line b). 


\subsection{Surface Wetting Behaviour of RC/MMT Nanocomposite Films}

Contact angle measurements of prepared films were considered to evaluate the hydrophobicity of thin films. Figure 8 demonstrates the contact angle variation of the prepared films in $10 \mathrm{~s}$ with MMT loading. The contact angle value that is $30.5^{\circ} \mathrm{C}$ in pure $\mathrm{RC}$ has increased up to $88.5^{\circ} \mathrm{C}$ when MMT loading is $5 \mathrm{wt} \%$. A material is hydrophilic if its water contact angle is less than $90^{\circ} \mathrm{C} .{ }^{34}$ This denotes that MMT can reduce hydrophilic nature of RC. According to Rasike De Silva et al., a surface is hydrophobic if the ingredients are compact and interactive with each other which implies that MMT is interactive with RC since the addition of MMT reaches the surfaces hydrophobic. ${ }^{34}$

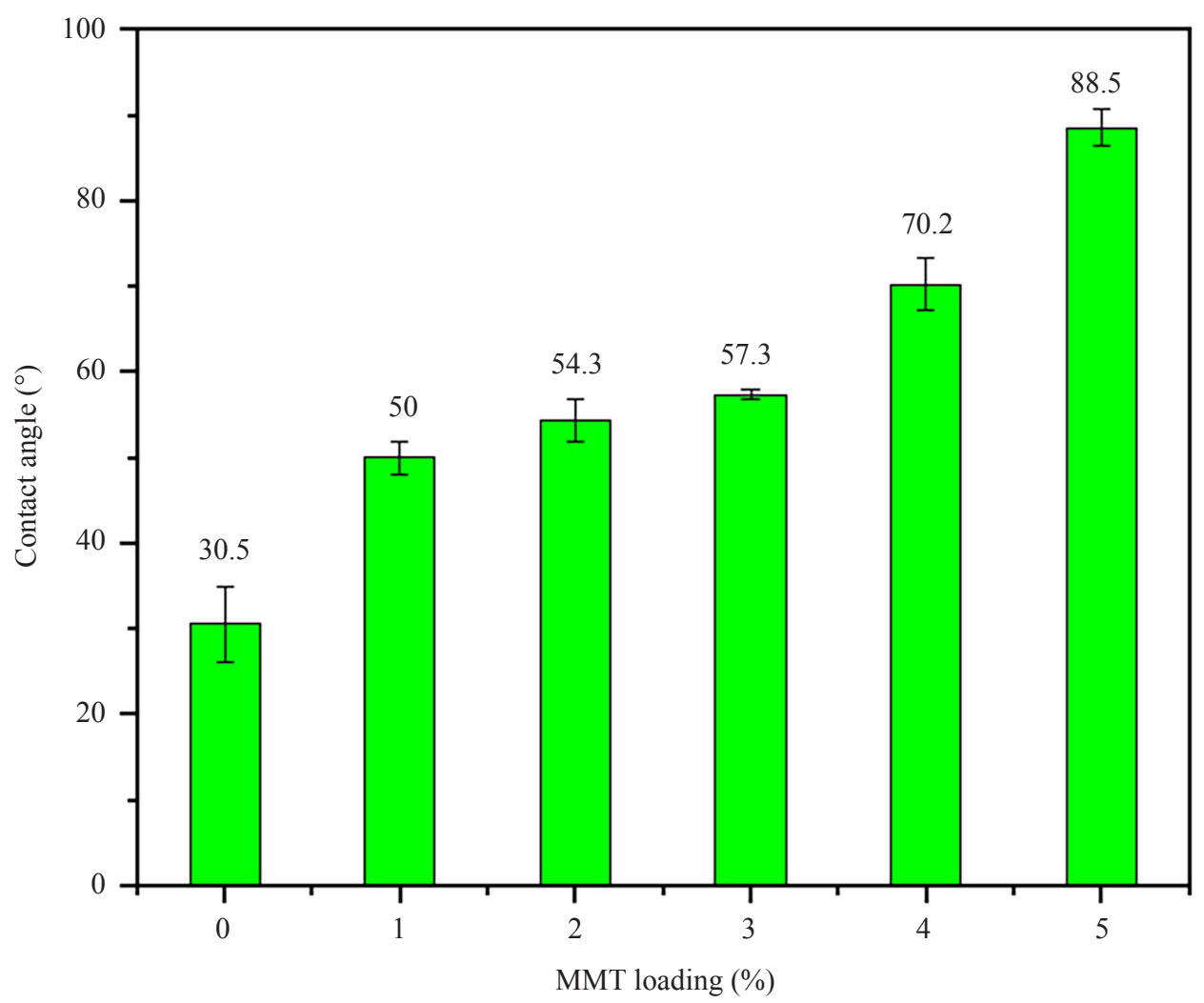

Figure 8: Variation of contact angle of RC films in $10 \mathrm{~s}$ with added MMT content. 


\section{CONCLUSION}

RC nanocomposite films were successfully prepared by incorporating MMT in the $\mathrm{MCC}$ dissolution system inside [BMIM] $\mathrm{Cl}$ and subsequent solution casting, coagulation and drying. FTIR spectrums confirm that MMT does not interfere with the basic chemical structure of cellulose as well as the spectrums further prove the non-derivatising behaviour of [BMIM]Cl. Increased amount of MMT provides improved TS and maximum TS was obtained at $4 \mathrm{wt} \%$ of MMT. According to SEM, smooth morphology is associated when the MMT loading is $3 \mathrm{wt} \%$. TGA results show that the thermal degradation temperature is raised with the addition of MMT into RC. The higher the MMT content, the lower the water absorption of $\mathrm{RC}$ nanocomposite films will be. Contact angle measurements denote that addition of MMT brings RC less hydrophilic. Regarding water absorption and contact angle, the most preferred amount of MMT is $5 \mathrm{wt} \%$ since both of these properties were enhanced with MMT content. But when the MMT content is $5 \mathrm{wt} \%$, the morphology becomes a coarse structure as a result of MMT agglomeration at high loadings (Section 3.2) while decreasing mechanical strength. Hence, concerning the overall figure, $34 \mathrm{wt} \%$ of MMT can be recommended to synthesise OPEFBbased nanocomposites for numerous RC-based applications such as packaging, photocatalytic and electrically conductive thin films.

\section{ACKNOWLEDGEMENTS}

This work was supported by Fundamental Research Grant Scheme (FRGS) 203/ PTEKIND/6711819 from the Ministry of Higher Education Malaysia.

\section{REFERENCES}

1. Wang, S., Lu, A. \& Zhang, L. (2016). Recent advances in regenerated cellulose materials. Prog. Polym. Sci., 53, 169-206. https://doi.org/10.1016/j. progpolymsci.2015.07.003

2. Soheilmoghaddam, M. et al. (2014). Regenerated cellulose/ $\beta$-cyclodextrin scaffold prepared using ionic liquid. Mater. Lett., 135, 210-213. https://doi.org/10.1016/j. matlet.2014.07.169

3. Pinkert, A. et al. (2009). Ionic liquids and their interaction with cellulose. Chem. Rev., 109(12), 6712-6728. https://doi.org/10.1021/cr9001947

4. Park, S. et al. (2017). Biopolymer-based functional composites for medical applications. Prog. Polym. Sci., 68, 77-105. https://doi.org/10.1016/j. progpolymsci.2016.12.003 
5. Zailuddin, N. L. I. \& Husseinsyah, S. (2016). Tensile properties and morphology of oil palm empty fruit bunch regenerated cellulose biocomposite films. Proced. Chem., 19, 366-372. https://doi.org/10.1016/j.proche.2016.03.025

6. Pujiasih, S. et al. (2018). Silylation and characterization of microcrystalline cellulose isolated from indonesian native oil palm empty fruit bunch. Carbohydr. Polym., 184, 74-81. https://doi.org/10.1016/j.carbpol.2017.12.060

7. Collazo-Bigliardi, S., Ortega-Toro, R. \& Chiralt Boix, A. (2018). Isolation and characterisation of microcrystalline cellulose and cellulose nanocrystals from coffee husk and comparative study with rice husk. Carbohydr. Polym., 191, 205215. https://doi.org/10.1016/j.carbpol.2018.03.022

8. Suhas, G. et al. (2016). Cellulose: A review as natural, modified and activated carbon adsorbent. Bioresour. Technol., 216, 1066-1076. https://doi.org/10.1016/j. biortech.2016.05.106

9. Xia, G. et al. (2016). Cellulose-based films prepared directly from waste newspapers via an ionic liquid. Carbohydr. Polym., 151, 223-229. https://doi.org/10.1016/j. carbpol.2016.05.080

10. Theo, W. L. et al. (2017). Optimisation of oil palm biomass and palm oil mill effluent (POME) utilisation pathway for palm oil mill cluster with consideration of BioCNG distribution network. Energy, 121, 865-883. https://doi.org/10.1016/j. energy.2017.01.021

11. Abdulrazik, A. et al. (2017). Multi-products productions from malaysian oil palm empty fruit bunch (EFB): Analyzing economic potentials from the optimal biomass supply chain. J. Clean. Prod., 168, 131-148. https://doi.org/10.1016/j. jclepro.2017.08.088

12. Abdul Khalil, H. P. S. et al. (2016). A review on chitosan-cellulose blends and nanocellulose reinforced chitosan biocomposites: Properties and their applications. Carbohydr. Polym., 150, 216-226. https://doi.org/10.1016/j.carbpol.2016.05.028

13. Mohamad Haafiz, M. K. et al. (2013). Isolation and characterization of microcrystalline cellulose from oil palm biomass residue. Carbohydr. Polym., 93(2), 628-634. https://doi.org/10.1016/j.carbpol.2013.01.035

14. Hussin, M. H. et al. (2016). Physicochemical of microcrystalline cellulose from oil palm fronds as potential methylene blue adsorbents. Int. J. Biol. Macromol., 92, 11-19. https://doi.org/10.1016/j.ijbiomac.2016.06.094

15. Haafiz, M. K. M. et al. (2013). Properties of polylactic acid composites reinforced with oil palm biomass microcrystalline cellulose. Carbohydr. Polym., 98(1), 139-145. https://doi.org/10.1016/j.carbpol.2013.05.069

16. Mohd, N. et al. (2017). Dissolution of cellulose in ionic liquid: A review. AIP Conf. Proc., 1809, 1-14. https://doi.org/10.1063/1.4975450

17. Nor Amalini, A. et al. (2019). Relationship between dissolution temperature and properties of oil palm biomass based-regenerated cellulose films prepared via ionic liquid. Mater. Chem. Phys., 221, 382-389. https://doi.org/10.1016/j. matchemphys.2018.09.028

18. Fink, H. P. et al. (2001). Structure formation of regenerated cellulose materials from NMMO-solutions. Prog. Polym. Sci., 26(9), 1473-1524. https://doi.org/10.1016/ S0079-6700(01)00025-9. 
19. Turner, M. B. et al. (2004). Production of bioactive cellulose films reconstituted from ionic liquids. Biomacromol., 5(4), 1379-1384. https://doi.org/10.1021/ bm049748q

20. Chemistry, G., Anastas, P. \& Agency, E. P. (2007). Studies on staged precipitation of cellulose from ionic liquid by compressed carbon dioxide. Green Chem., 12(3), 1-10. https://doi.org/10.1039/c0xx00000x

21. Lara-Serrano, M. et al. (2019). Fractionation of lignocellulosic biomass by selective precipitation from ionic liquid dissolution. Appl. Sci., 9(9), 1-17. https://doi.org/10.3390/app9091862

22. Phinichka, N. \& Kaenthong, S. (2018). Regenerated cellulose from high alpha cellulose pulp of steam-exploded sugarcane bagasse. J. Mater. Res. Technol., 7(1), 55-65. https://doi.org/10.1016/j.jmrt.2017.04.003

23. Tunç, S. \& Duman, O. (2010). Preparation and characterization of biodegradable methyl cellulose/montmorillonite nanocomposite films. Appl. Clay Sci., 48(3), 414-424. https://doi.org/10.1016/j.clay.2010.01.016

24. Nouri, A. et al. (2018). Enhanced antibacterial effect of chitosan film using montmorillonite/CuO nanocomposite. Int. J. Biol. Macromol., 109, 1219-1231. https://doi.org/10.1016/j.ijbiomac.2017.11.119

25. Majdzadeh-Ardakani, K., Navarchian, A. H. \& Sadeghi, F. (2010). Optimization of mechanical properties of thermoplastic starch/clay nanocomposites. Carbohydr. Polym., 79(3), 547-554. https://doi.org/10.1016/j.carbpol.2009.09.001

26. Hanid, N. A. et al. (2014). Development of regenerated cellulose/halloysites nanocomposites via ionic liquids. Carbohydr. Polym., 99, 91-97. https://doi. org/10.1016/j.carbpol.2013.07.080

27. Soheilmoghaddam, M. et al. (2014). Characterization of bio regenerated cellulose/ sepiolite nanocomposite films prepared via ionic liquid. Polym. Test., 33, 121-130. https://doi.org/10.1016/j.polymertesting.2013.11.011

28. Mahmoudian, S. et al. (2012). Preparation of regenerated cellulose/montmorillonite nanocomposite films via ionic liquids. Carbohydr. Polym., 88(4), 1251-1257. https://doi.org/10.1016/j.carbpol.2012.01.088

29. Sudiyani, Y. et al. (2013). Utilization of biomass waste empty fruit bunch fiber of palm oil for bioethanol production using pilot-scale unit. Energy Proced., 32, 31-38. https://doi.org/10.1016/j.egypro.2013.05.005

30. Chen, H. Z., Wang, N. \& Liu, L. Y. (2012). Regenerated cellulose membrane prepared with ionic liquid 1-butyl-3-methylimidazolium chloride as solvent using wheat straw. J. Chem. Technol. Biotechnol., 87(12), 1634-1640. https://doi. org/10.1002/jctb.3802

31. Reddy, K. O. et al. (2017). Preparation and characterization of regenerated cellulose films using borassus fruit fibers and an ionic liquid. Carbohydr. Polym., 160, 203-211. https://doi.org/10.1016/j.carbpol.2016.12.051

32. Yang, Z. et al. (2010). Crystallization behavior of poly( $\varepsilon$-caprolactone)/layered double hydroxide nanocomposites. J. Appl. Polym. Sci., 116(5), 2658-2667. https://doi.org/10.1002/app 
33. Zhang, X. et al. (2018). Preparation and characterization of regenerated cellulose film from a solution in lithium bromide molten salt hydrate. Polym., 8(6), 1-13. https://doi.org/10.3390/polym10060614

34. Silva, R. D. et al. (2015). Development of a novel regenerated cellulose composite material. Carbohydr. Polym., 121, 382-387. https://doi.org/10.1016/j. carbpol.2014.12.018 